\title{
Absorption of Pathogenic Autoantibodies by the Extracellular Domain of Pemphigus Vulgaris Antigen (Dsg3) Produced by Baculovirus
}

\author{
Masayuki Amagai, “‡ Takashi Hashimoto, ${ }^{*}$ Nobuyoshi Shimizu, ${ }^{\S}$ and Takeji Nishikawa* \\ Departments of ${ }^{*}$ Dermatology and ${ }^{\S}$ Molecular Biology, Keio University School of Medicine, and ${ }^{\ddagger}$ Tokyo Electric Power Hospital, \\ Tokyo, 160 Japan
}

\begin{abstract}
Pemphigus vulgaris (PV) is an autoimmune blistering disease, in which autoantibodies against PV antigen (PVA or Dsg3) play a pathogenic role in inducing blister formation. Bacterial fusion proteins of PVA failed to absorb pathogenic autoantibodies from PV patients' sera probably because they did not represent the proper conformation. Therefore, a chimeric protein, PVIg, consisting of the whole extracellular domain of PVA and the constant region of human IgG1, was produced in either in COS7 or in insect Sf9 eucaryotic cells. Both PVIg-COS7 and PVIg-Sf9 were recognized by all of the $35 \mathrm{PV}$ sera tested, but not by any of 10 pemphigus foliaceus (PF), 16 Brazilian PF, 10 bullous pemphigoid, or five normal control sera. Incubation of PV patients' sera with PVIg-Sf9 removed heterogeneous autoantibodies and significantly reduced their immunofluorescence titers on normal human epidermis, although PVIg-Sf9 did not affect the titers of PF sera at all. Furthermore, PVIg-Sf9 absorbed pathogenic autoantibodies from patients' sera and prevented gross blister formation in a neonatal mouse model for pemphigus. These results indicate that this baculovirus product has the proper conformation of the authentic PVA and that its conformation is important in pathogenicity of pemphigus. (J. Clin. Invest. 1994. 94:59-67.) Key words: cadherin - autoimmune disease - desmoglein - neonatal mouse model • therapy
\end{abstract}

\section{Introduction}

Pemphigus vulgaris $(\mathrm{PV})^{1}$ is a life-threatening autoimmune blistering disease of skin and mucous membranes. Autoantibodies found in patients with PV bind the keratinocyte cell surface

Address correspondence to Dr. Masayuki Amagai, Dermatology Division, Tokyo Electric Power Hospital, 9-2 Shinanomachi, Shinjuku-ku, Tokyo, 160 Japan.

Received for publication 3 January 1994 and in revised form 25 February 1994.

1. Abbreviations used in this paper: $\mathrm{BP}$, bullous pemphigoid; $\mathrm{BPF}$, Brazilian pemphigus foliaceus; CMV, cytomegalovirus; Dsg, desmoglein; PF, pemphigus foliaceus; PV, pemphigus vulgaris; PVA, the $130-\mathrm{kD}$ pemphigus vulgaris antigen; PVIg, the chimeric molecule with the extracellular domain of PVA and the constant region of human IgG1.

J. Clin. Invest.

(c) The American Society for Clinical Investigation, Inc. 0021-9738/94/07/0059/09 \$2.00

Volume 94, July 1994, 59-67 and cause loss of cell adhesion of keratinocyte with resultant blister formation (1). The pathogenic roles of PV autoantibodies of IgG subclass have been established from a number of observations. First, disease activity in patients often correlates with anti-cell surface antibody titer, as determined by indirect immunofluorescence (2). Second, neonates of mothers with PV may have transient disease due to maternal IgG that crosses the placenta (3). As maternal antibody is catabolized, disease subsides. Third, IgG from patients with pemphigus alone, without complement or inflammatory cells, can induce loss of cellcell adhesion, with the same histology as seen in patients, in skin organ culture $(4,5)$. Lastly, passive transfer of IgG from patients sera to neonatal mice results in loss of cell-cell adhesion and blisters with typical histological findings (6).

A target molecule of these pathogenic autoantibodies, PV antigen (PVA), has been characterized as a $130-\mathrm{kD}$ glycoprotein by immunoprecipitation and immunoblot analyses (7-10). Recently, cDNA for PVA has been isolated by immunoscreening a human keratinocyte expression cDNA library with affinity-purified PV IgG (11). The deduced amino acid sequences of PVA showed marked homology with members of $\mathrm{Ca}^{2+}$ dependent cell adhesion molecules, cadherins $(12,13)$, especially with desmoglein I (Dsg1 ) (14-17), which is a transmembrane glycoprotein of desmosome complex and also the autoantigen for pemphigus foliaceus (PF), another type of autoimmune blistering disease of the skin (1).

PVA (Dsg3) is similar in overall structure to classic cadherins (11). Like classic cadherins, PVA has five extracellular subdomains of approximately equal size, termed EC1 (amino terminus) through EC5 (carboxy terminus of the extracellular portion ). PVA is synthesized as a precursor protein with a signal peptide and a prosequence and the cleavage of the prosequence would result in a mature PVA as seen in classic cadherins. Correct proteolytic cleavage of prosequence is required for the cell adhesive function of classic cadherins (18). PVA has two $\mathrm{N}$-linked glycosylation sites in EC1 and EC2 domains, which are also found in Dsg1 at equivalent positions. Studies of classic cadherins have shown that the 113 amino-terminal residues (EC1 and part of the EC2 domain) are important for determining binding function and specificity of binding (19).

In a previous study we used patient sera to map the major epitopes on PVA and to determine if antibodies against certain epitopes were pathogenic when passively transferred to neonatal mice (20). These studies were performed using fusion proteins, made in bacteria, with cDNA coding for various extracellular subdomains of PVA. We screened patient sera on these bacterial fusion proteins by immunoblotting, a technique that has been used to define immunodominant epitopes on several other autoantigens $(21-24)$. Using this method we found that subdomains EC1, EC2, and EC4 contained immunodominant epitopes and that antibodies affinity purified from patients sera on a 


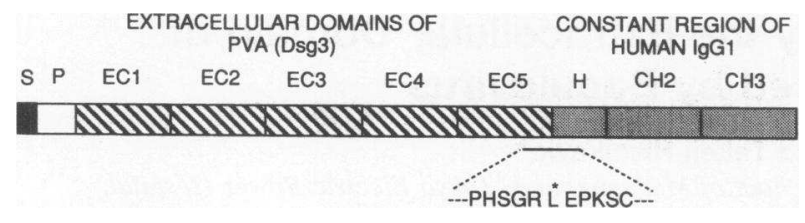

Figure 1. Molecular structure of PVIg, a secreted form of PVA chimeric molecule. PVIg contains the signal peptide $(S)$, the prosequence $(P)$, the whole extracellular domain of PVA $(E C 1-5)$, and the constant region of human IgG1, including hinge $(H), \mathrm{CH} 2$, and $\mathrm{CH} 3$ regions. The amino acid sequence around the fused site is shown and one leucine was introduced to create a new restriction site.

bacterial fusion protein containing EC1-2, but not EC3-5, were capable of causing histologic blisters of PV when passively transferred to neonatal mice. Therefore, we concluded that at least one pathogenic epitope was located in the EC1-2 subdomain, an area thought to be important in cadherin homophilic adhesion.

However, searching for immunodominant and pathogenic epitopes with bacterial fusion proteins has severe limitations. Various posttranslational processes such as glycosylation, proteolytic processing, and protein folding are fundamentally different in bacteria compared with eucaryotic cells. Since many protein binding sites are conformational (25), and therefore, potentially dependent on these processes, bacterial fusion proteins may lack many epitopes found on the native antigen. Furthermore, the bacterial proteins of PVA were insoluble and used only after solubilized with denaturing agents, such as SDS or urea. These limitations of the bacterial fusion proteins should account for our previous findings. First, $\sim 25 \%$ of PV sera tested did not react with any of the bacterial fusion proteins spanning the full extracellular domain of PVA (20); second, even the fusion protein containing major immunogenic domains was recognized only by $\sim 60 \%$ of PV sera tested (20); third, the incubation of PV sera with these bacterial proteins did not reduce immunofluorescence titers on cryo-sectioned skin containing native PVA (unpublished observation); last, although we found a pathogenic epitope in the EC1-2 domain, most pathogenic epitopes were not represented by our fusion proteins because these bacterial proteins failed to absorb pathogenic autoantibodies from PV patients' sera (20). The purpose of this study is to determine if we could produce genetically engineered PVA that represents the proper conformation of PVA and contains most or all of the pathogenic epitopes. Because of the limitations of bacterial fusion proteins, we constructed vectors to express the entire extracellular domain of PVA in eucaryotic cells. We then determined if such proteins contained epitopes that all PV sera could recognize. Subsequently, we produced it in large quantities by baculovirus expression system to determine if it contained all the relevant pathogenic epitopes that are involved in blister formation when PV IgG is passively transferred to neonatal mice.

\section{Methods}

Human sera. Sera from patients with clinically and histologically typical PV showed characteristic cell surface immunofluorescence staining on normal human epidermis and immunoblotted the 130-kD PVA (10). PV sera Nos. 11,12 , and 13 were obtained by plasmapheresis. Disease

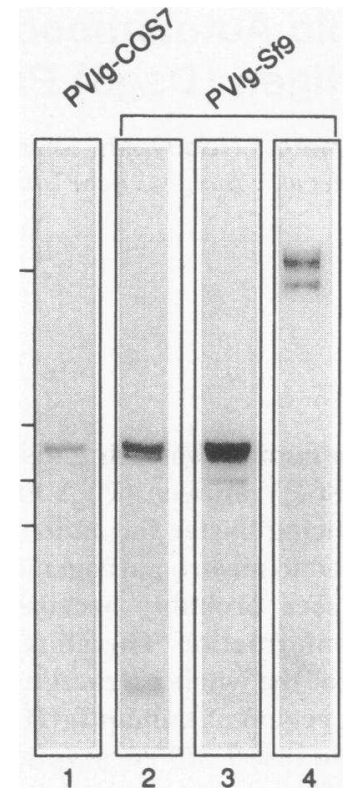

Figure 2. Production of PVIg chimeric protein in COS7 cells ( $P V I g$-COS7) and Sf 9 cells ( $P V I g-S f 9)$. The PVIg molecules were purified from culture media with protein A, separated on SDS-

PAGE either in reduced or nonreduced condition, transferred to a PVDF membrane, and visualized with alkalinephosphatase conjugated anti-human IgG antibodies. Precursor proteins of PVIg-Sf 9 were also purified from cell extracts of infected Sf 9 cells. Lane 1 , secreted PVIg-COS7, reduced condition; lane 2, secreted PVIg-Sf 9, reduced condition; lane 3 , precursor proteins of PVIg-Sf 9, reduced condition; lane 4, secreted PVIg-Sf 9, nonreduced condition. Bars on the left indicate molecular weight standards of, from top to bottom, $200,116,97$, and $80 \mathrm{kD}$.

control sera were obtained from patients with clinically and histologically typical PF, Brazilian PF (BPF), and bullous pemphigoid (BP). $\mathrm{PF}$ and BPF are autoimmune blistering diseases of the skin, in which autoantibodies bind Dsg1. These disease-control sera showed characteristic immunofluorescence findings. Normal human sera were also used as controls.

Construction of PVIg expression plasmids. A chimeric molecule which has the extracellular domain of PVA and the constant region of human IgG1 (PVIg) was produced either in COS7 cells by transient transfection or in Sf 9 insect cells by baculovirus expression system (see Fig. 1). Basically, desired cDNAs were amplified by polymerase chain reaction (PCR) using synthetic oligonucleotides complementary to sequences flanking the cDNA regions to be amplified. Oligonucleotides were designed to allow the creation of restriction enzyme cleavage sites or coding sequences for peptides to be added. Typically, 20 to 25 cycles were conducted consisting of $1 \mathrm{~min}$ at $94^{\circ} \mathrm{C}, 2 \mathrm{~min}$ at $55^{\circ} \mathrm{C}$, and $3 \mathrm{~min}$ at $72^{\circ} \mathrm{C}$, using the reaction buffer recommended by the manufacturer (Perkin Elmer Cetus, Norwalk, CT).

To construct an expression vector for COS7 cells, cDNA coding the extracellular domain of PVA was PCR amplified on pcDNA1-PVECIII, a mammalian expression vector containing a chimeric molecule with the extracellular domain of human PVA and the cytoplasmic domain of mouse E-cadherin (26), using the $\mathrm{T} 7$ primer in the vector sequence as a 5 ' primer and a 3 ' primer with following sequence: 5 '-CCT-GCTCGA-GCC-TCC-CTG-AGT-GCG-GCC-T-3' (encoding the antisense sequences immediately upstream of the end of EC5 domain of PVA and a Xhol site). This PCR product has 5 ' noncoding region and the coding region covering the signal peptide, prosequence and the entire extracellular domain of PVA (nucleotides 1-1929) (11). cDNA encoding the constant region of human IgG1 was generated by PCR amplification on pTJ5 (a plasmid containing cDNA encoding a part of hinge region, $\mathrm{CH} 2$, and $\mathrm{CH} 3$ domain regions, a generous gift from Drs. Satoshi Nakamura and Kazuhiko Souma; Biotechnology Research Laboratory, Teijin Ltd.) (27) with primers with the following sequences: 5 ' primer, 5'-CCT-GCT-CGA-GCC-CAA-ATC-TTG-TGA-CAA-AAC-TCACAC-ATG-CCC-ACC-GTG-CCC-A-3' (encoding the whole sequences for the hinge region and a Xhol site). $3^{\prime}$ primer, 5'-CCA-TCT-AGATCA-TTT-ACC-CGG-GGA-CAG-3' (encoding antisense sequences of immediately upstream of the stop codon and a XbaI site). The PVA PCR product and the IgG1 PCR product were digested with NotI-XhoI and XhoI-XbaI, respectively, and ligated together to NotI-XbaI-cut 

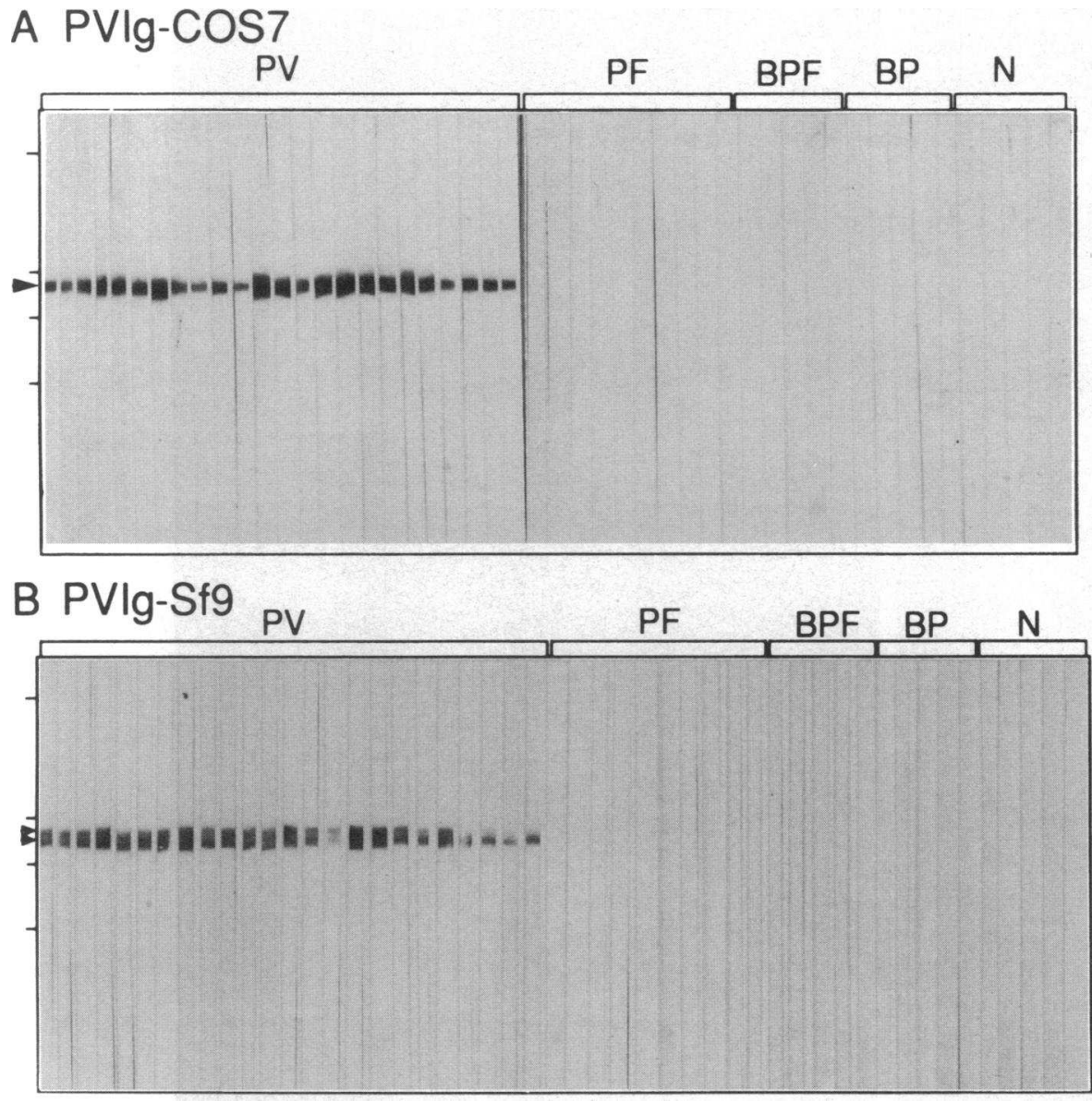

Figure 3. Immunoblot analysis of PVIgCOS7 and PVIg-Sf 9 with PV and control sera. Blotted PVIg-COS7 and PVIg-Sf9 were incubated sequentially with human sera (PV, PF, BPF, BP, and normal $[N]$ sera), anti-human IgG4 mouse monoclonal antibody, and with alkaline-phosphatase conjugated anti-mouse IgG antibodies. Arrow heads indicate the location of PVIgs. PVIg-Sf9 is identified as a doublet and many PV sera react more strongly to the lower band. Note the clear difference between positive staining with PV sera and negative staining with disease and normal control sera. Bars on the left indicate molecular weight standards of, from top to bottom, 200, 116, 97, and $80 \mathrm{kD}$.
pcDNA1/Amp, an eucaryote expression vector with the cytomegalovirus (CMV) promoter (Invitrogen, San Diego, CA). The final construct was designated pcDNA1-PVIg.

For expression of the chimeric molecule in baculovirus system, the insert in pcDNA1-PVIg was transferred to a baculovirus transfer vector, pEVmod (a generous gift from Dr. Lois K. Miller, Department of Entomology, the University of Georgia) (28) with some modifications. A 2.0-kb EcoRI-Apal fragment, which contains most of the coding sequences for PVIg but misses 5' 570 bp of the coding region of PVA, was obtained from DNA1-PVIg and subcloned into pBluescript II KS (Stratagene, La Jolla, CA) to add KpnI site at the 3' end. A cDNA encoding the 5' 570 bp of PVA was obtained by PCR amplification on pcDNA1-PVECIII with primers with the following sequences: 5' primer, 5'-TAA-GGA-ATTCAG-ATC-TCG-CCA-TGG-GGC-TCT-TCC-CCA-GAA-C-3' (encoding sequences immediately downstream of the translation initiation site of PVA and the Kozak consensus sequence at translation initiation site [29] and a BglII site). 3' primer, 5'-CCC-TGC-AGA-AAC-ATT-GGG-AAGTTA-TC-3' (encoding antisense sequences immediately upstream of the end of EC2 domain of PVA). The PCR product was digested with BglIIEcoRI and ligated together with the EcoRI-KpnI PVIg fragment and BglII-KpnI-cut pEVmod vector. This construct does not contain heterogeneous sequences in the 5' noncoding region of PVA which may alter the expression in baculovirus system (30), and was designated pEVmod-PVIg.

Production of PVIg in COS7 cells. pcDNA1-PVIg was transiently transfected into COS7 cells using Lipofectin (GIBCO BRL, Gaithersburg, MD). Typically, a 100-mm semiconfluent plate of COS7 cells were transfected with $10 \mu \mathrm{g}$ of the plasmid DNA and $50 \mu \mathrm{l}$ of Lipofectin in $5 \mathrm{ml}$ of serum-free Dulbecco's modified Eagle medium (DME) and after $4 \mathrm{~h}$ of incubation at $37^{\circ} \mathrm{C}$ an equal volume of DME with $20 \%$ fetal calf serum (FCS) was added and incubated overnight. Next day the culture medium was removed and replaced with $6 \mathrm{ml}$ of serum-free DME. Incubation was continued for $3 \mathrm{~d}$ at $37^{\circ} \mathrm{C}$, then the medium was collected and fresh serum-free medium was added. After an additional $3 \mathrm{~d}$ at $37^{\circ} \mathrm{C}$, the spent medium was again collected and cells were discarded. The collected medium was centrifuged to remove nonadherent cells and debris, pooled and stored at $-70^{\circ} \mathrm{C}$ until use. In average the supernatant contained $\sim 0.1-0.5 \mu \mathrm{g} / \mathrm{ml}$ of the PVIg-COS7 protein, as measured by protein assay kit (Bio Rad Laboratories, Richmond, CA).

Production of PVIg in Sf9 cells by baculovirus expression. pEVmod-PVIg was cotransfected with the BaculoGold baculovirus DNA with a lethal deletion (Pharmingen, San Diego, CA) into a cultured insect Sf 9 cells, and recombinant baculovirus producing PVIg-Sf 9 was obtained. Typically, approximately $3 \times 10^{6} \mathrm{Sf} 9$ cells were plated on a $60-\mathrm{mm}$ tissue culture dish, and incubated at $27^{\circ} \mathrm{C}$ for $15 \mathrm{~min}$ to allow them to attach to the plate. In the meantime, DNA-Lipofectin mixture was prepared by incubating $2 \mu \mathrm{g}$ of the pEVmod-PVIg DNA, $0.5 \mu \mathrm{g}$ of the BaculoGold DNA, and $30 \mu \mathrm{l}$ of Lipofectin in $1.5 \mathrm{ml}$ of serumfree Grace's insect cell culture medium at room temperature for $15 \mathrm{~min}$. The Sf 9 cells were washed twice with serum-free Grace's medium and $1.5 \mathrm{ml}$ of serum-free Grace's medium was added. The DNA-Lipofectin mixture was added dropwise and transfected cells were incubated at $27^{\circ} \mathrm{C}$ for $4 \mathrm{~h}$. Then, the cells were washed once with serum-free Grace medium and incubated in Grace's medium with $10 \% \mathrm{FCS}$ at $27^{\circ} \mathrm{C}$ for 4 d. Then, the supernatant was collected and used to amplify recombinant baculovirus by infecting semiconfluent Sf 9 cells in a $100-\mathrm{mm}$ dish and incubating for 3-5 d. High titer of recombinant baculovirus stock was obtained after several rounds of reamplification.

The supernatant of Sf 9 cells that were infected with high-titer recombinant virus and cultured for $5 \mathrm{~d}$ was stored at $-70^{\circ} \mathrm{C}$ after removing 

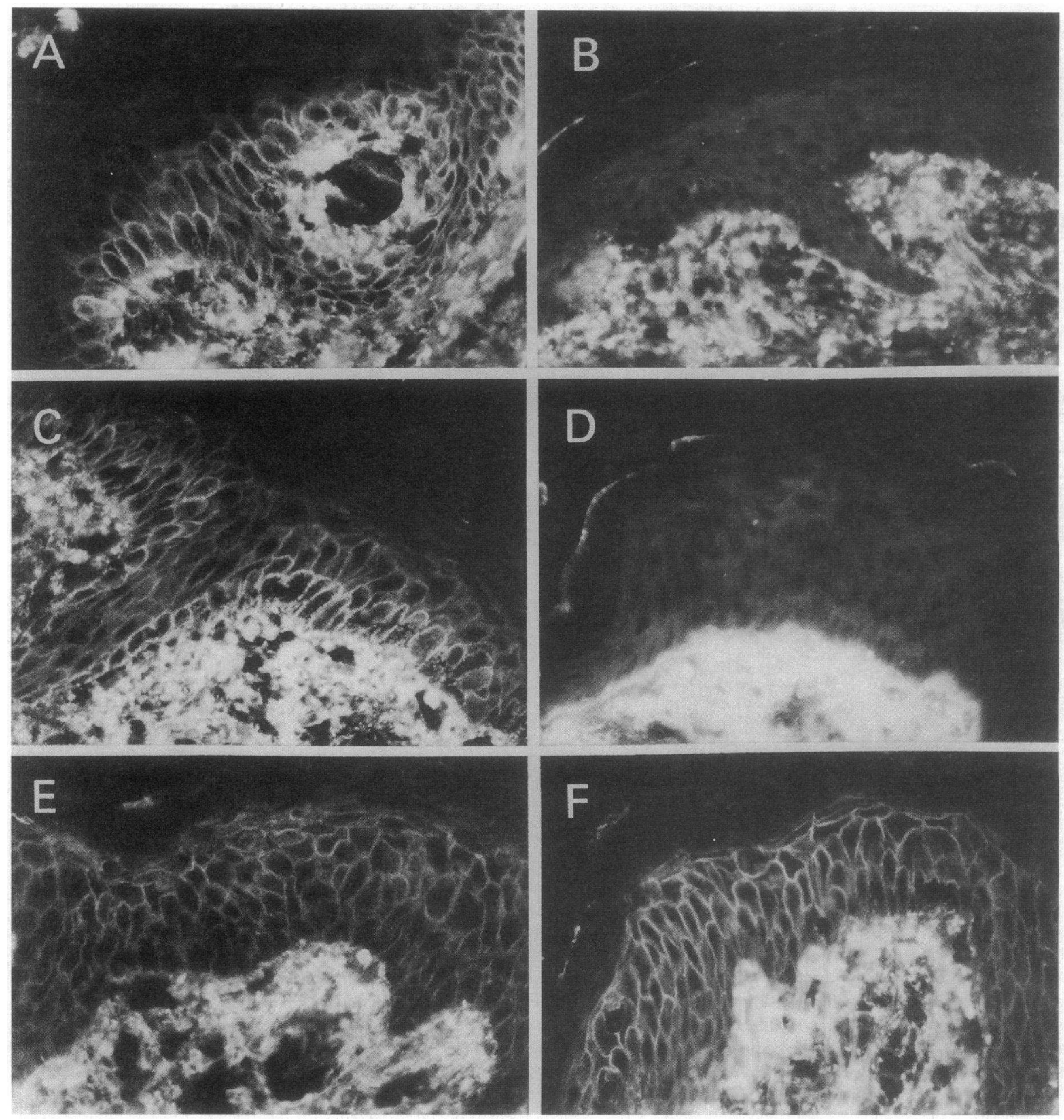

Figure 4. Absorption of PV autoantibodies with PVIg-Sf9. Two PV sera (PV No. 1, $A$ and $B$; PV No. 2, $C$ and $D ; 1: 40$ dilution, see also Table I) and a PF serum ( $E$ and $F ; 1: 160$ dilution) were incubated either with PVIg-Sf9 supernatant $(B, D$, and $F)$ or control supernatant $(A, C$, and $E$ ), then subjected to immunofluorescence staining on normal human skin. The PVIg-Sf 9 treatment removed the reactivity of PV sera with keratinocyte cell surface completely, but not that of PF sera. $\times 400$.

cell debris by centrifugation. On average, the supernatant contained $\sim 5-10 \mu \mathrm{g} / \mathrm{ml}$ of the PVIg-Sf 9 protein, as measured by the protein assay kit (Bio Rad Laboratories). The extracts of infected cells were obtained by extracting cells with $3 \mathrm{ml}$ of lysis buffer (PBS [-], 1\% NP-40, $1 \mathrm{mM}$ PMSF, $20 \mu \mathrm{g} / \mathrm{ml}$ aprotinin) and centrifuging to remove nuclei and debris.

Immunoblot analysis of the PVIg chimeric molecules. To concentrate PVIg chimeric molecules, typically, $50 \mu \mathrm{l}$ volume of protein A-sepharose (Pharmacia, Uppsala, Sweden) was added to $5 \mathrm{ml}$ of spent culture supernatant or cell extract, incubated at $4^{\circ} \mathrm{C}$ overnight, washed twice with PBS $(-)$, and resuspended with $50-100 \mu \mathrm{l}$ of $2 \times$ SDS sample buffer ( $125 \mathrm{mM}$ Tris-HCl, pH 7.5, $2 \%$ SDS, $0.005 \%$ bromophenol blue, $20 \%$ glycerol, with or without $5 \% 2$-mercaptoethanol).
The concentrated PVIg proteins were separated by SDS-PAGE, and transferred to PVDF membranes, Immobilon (Millipore Corp., Bedford, MA). To detect the PVIg molecules, the membrane was incubated with 1:1,000 dilution of alkaline phosphatase-conjugated goat anti-human IgG antibodies (Zymed Laboratories, Inc., San Francisco, CA) at room temperature for $1 \mathrm{~h}$. To see reactivity of $\mathrm{PV}$, disease control, or normal control human sera against PVIg molecules, the membrane was first incubated with 1:50 dilution of human sera (35 PV, $10 \mathrm{PF}, 16 \mathrm{BPF}, 10$ $\mathrm{BP}$, and 5 normal sera), then 1:30 dilution of mouse anti-human IgG4 antibody (Oxoid, Hants, England), and 1:1,000 dilution of alkaline phosphatase-conjugated goat anti-mouse IgG antibodies (Zymed Laboratories, Inc.).

Absorption of PV IgG with PVIg-Sf9. $10 \mu \mathrm{l}$ of patients' sera was 


\begin{tabular}{|c|c|c|c|c|c|c|c|}
\hline \multirow[b]{2}{*}{ Sera } & \multirow[b]{2}{*}{$\begin{array}{l}\text { Original } \\
\text { titer }\end{array}$} & \multicolumn{2}{|c|}{ Titer after absorption with } & \multirow[b]{2}{*}{ Age/sex } & \multicolumn{3}{|c|}{ Clinical information } \\
\hline & & Control & PVIg-Sf9 & & Duration* & Extent $^{*}$ & $\begin{array}{l}\text { Response } \\
\text { to steroid }\end{array}$ \\
\hline \multicolumn{8}{|c|}{ PV sera } \\
\hline 1 & 1280 & $>640$ & - & $41 / M$ & $3 \mathrm{yr}$ & + & $\mathrm{E}$ \\
\hline 2 & 1280 & $>640$ & - & $\mathrm{NA}^{\| \prime}$ & & & \\
\hline 3 & 320 & 320 & - & $40 / \mathrm{F}$ & $1 \mathrm{yr}$ & + & E \\
\hline 4 & 320 & 160 & - & $58 / \mathrm{F}$ & $2 \mathrm{yr}$ & ++ & E \\
\hline 5 & 160 & 160 & - & NA & & & \\
\hline 6 & 160 & 80 & - & NA & & & \\
\hline 7 & 640 & 640 & 20 & NA & & & \\
\hline 8 & 320 & 320 & 20 & NA & & & \\
\hline 9 & 160 & 160 & 40 & $60 / \mathrm{F}$ & $5 \mathrm{yr}$ & ++ & $\mathbf{E}$ \\
\hline 10 & 1280 & 1280 & 80 & NA & & & \\
\hline $11^{4}$ & 160 & 160 & 80 & $45 / F$ & $7 \mathrm{yr}$ & +++ & $\mathbf{P}$ \\
\hline $12^{1}$ & 640 & 640 & 160 & $31 / \mathrm{F}$ & $6 \mathrm{yr}$ & +++ & $\mathbf{P}$ \\
\hline $13^{1}$ & 640 & 640 & 160 & $35 / \mathrm{F}$ & $5 \mathrm{yr}$ & +++ & $\mathbf{P}$ \\
\hline 14 & 320 & 320 & 160 & $82 / \mathrm{F}$ & $10 \mathrm{yr}$ & +++ & $\mathbf{P}$ \\
\hline 15 & $>640$ & 1280 & 160 & $46 / M$ & $6 \mathrm{yr}$ & +++ & $\mathbf{P}$ \\
\hline 16 & $>640$ & 1280 & 320 & $65 / \mathrm{M}$ & $2 \mathrm{yr}$ & ++ & $\mathrm{E}$ \\
\hline 17 & $>640$ & 1280 & 1280 & $39 / \mathrm{M}$ & $4 \mathrm{yr}$ & +++ & $P$ \\
\hline \multicolumn{8}{|c|}{ PF sera } \\
\hline 1 & 1280 & $>640$ & $>640$ & & & & \\
\hline 2 & 320 & 320 & 320 & & & & \\
\hline 3 & 160 & 160 & 160 & & & & \\
\hline
\end{tabular}

* Duration of the disease when sera were obtained. ${ }^{\ddagger}$ Extent of the disease was indicated by; + , localized (i.e., oral lesions only); ++ , intermediate; +++ , generalized. ${ }^{8}$ Response to systemic corticosteroid is indicated by $E$, excellent, no need of other therapy; $P$, poor, requirement of other combined therapy, such as immunosuppressive drugs or plasmapheresis, relapses were often seen. "NA indicates data not available. 'PV sera Nos. 11, 12, and 13 were used for passive transfer into neonatal mice. See also Table II.

incubated at room temperature for $4 \mathrm{~h}$ with $190 \mu \mathrm{l}$ of culture supernatant of Sf 9 cells either with infection of PVIg-Sf 9 recombinant virus or without infection, serially diluted with phosphate-buffered saline with $0.5 \mathrm{mM} \mathrm{CaCl}_{2}$ (PBS-Ca), and applied to indirect immunofluorescence staining on normal human epidermis with 1:50 dilution of FITC-conjugated anti-human IgG antibodies (Dako, Copenhagen, Denmark) as a second antibody.

For neonatal mouse study, $10 \mathrm{ml}$ of each PV patient's serum was incubated at room temperature for $4 \mathrm{~h}$ with $50 \mathrm{ml}$ of either PVIg-Sf9 supernatant or noninfected control supernatant, and centrifuged at $13,000 \mathrm{~g}$ at $4^{\circ} \mathrm{C}$ for $30 \mathrm{~min}$ to remove aggregates. Then, IgG was prepared by precipitation with $40 \%$ ammonium sulfate, dialyzed against PBS-Ca, and concentrated with a microconcentrator, Centricon 100 (Amicon, Beverly, MA) to $1 \mathrm{ml}$ (1/10 volume of the original serum volume). These concentrated IgGs (100-150 $\mu$ l per mouse) were injected subcutaneously into neonatal BALB/c mice $(<24 \mathrm{~h}$ of age $)$ as described previously $(6,20)$. Neonatal mice were examined and biopsied 18-24 h after injection. The serial dilution of these concentrated IgGs was made at $2 \times, 4 \times$, and $8 \times$ to quantitate their pathogenic activities of gross blister formation in neonatal mice.

\section{Results}

Production and secretion of the PVA extracellular domain by COS7 cells. To make recombinant PVA proteins with the proper three-dimensional conformation, we designed a chimeric cDNA that encoded the signal peptide and prosequence of PVA as well as its entire extracellular domain and then, in frame, encoded the constant region of human IgG1 (Fig. 1). Therefore, the aminoterminal part of the protein should act just as normally translated PVA and the whole molecule should result in a secreted protein, which would be processed to the mature protein at the plasma membrane of a eucaryotic cell. The constant region of human IgG1 was introduced at the carboxy-terminal end for several reasons. First, it may enhance the stability of the engineered proteins. Second, it contains a hinge region that should prevent the IgG polypeptide from interfering conformationally with the PVA extracellular domain (31). Third, the constant region of IgG can be used for detection of the recombinant molecule with anti-human IgG antibodies (see below). Finally, the IgG region can be used to purify the recombinant protein with protein A. Several biologically active proteins have been produced using this strategy $(32-36)$.

A cDNA encoding this chimeric PVIg molecule was constructed in an eucaryotic expression vector containing the CMD promoter. Transient transfection of COS7 cells with this construct resulted in secretion of the chimeric molecule, PVIgCOS7, in cultured media, which was purified on protein A by a single step. Purified PVIg-COS7 was examined by immunoblot with alkaline-phosphatase conjugated anti-human IgG goat antibodies and detected as a single band, whose molecular weight was $\sim 110 \mathrm{kD}$ (Fig. 2, lane 1).

PVIg-COS7 was then subjected to immunoblot analysis with 

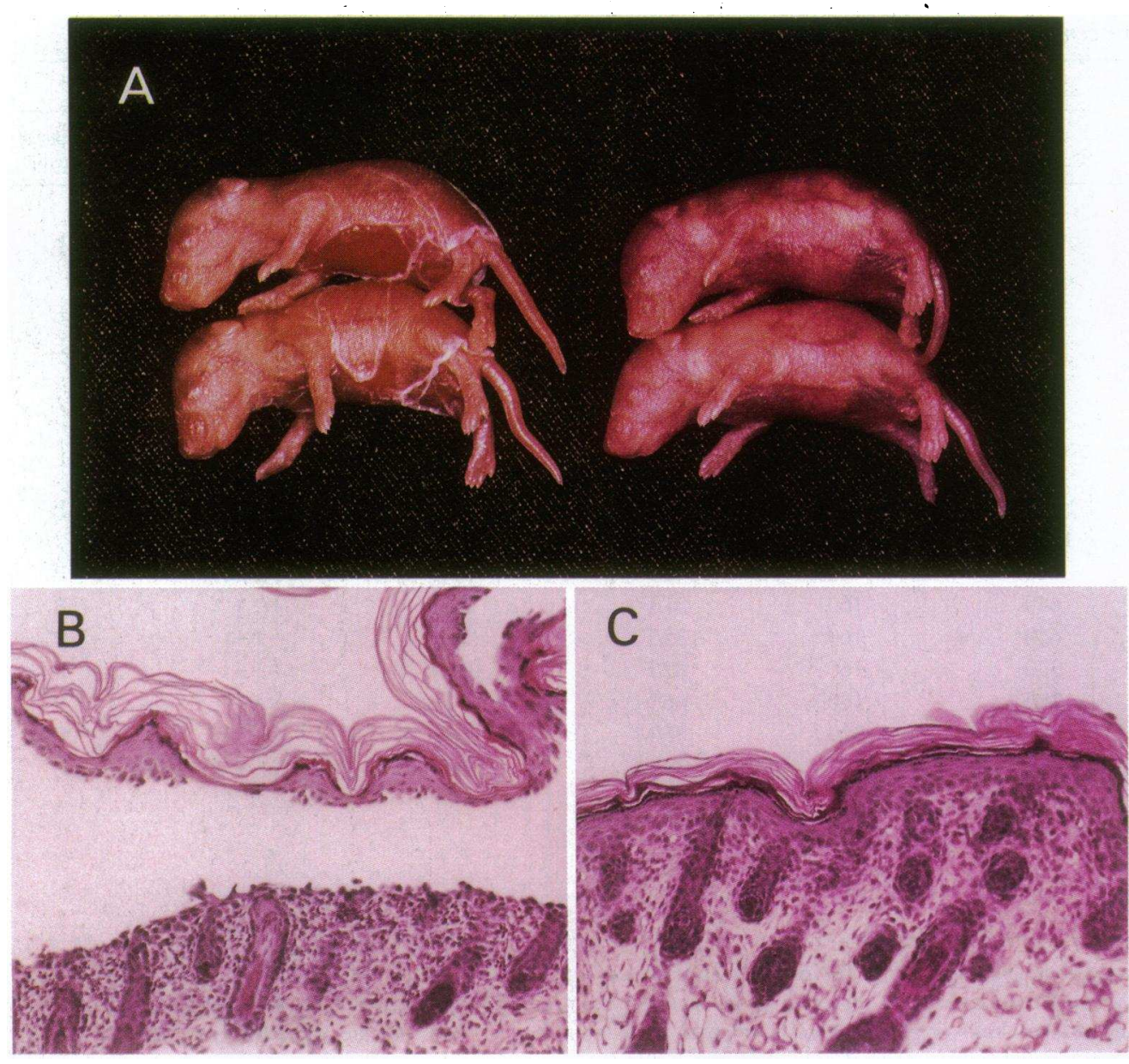

Figure 5. Prevention of gross blister formation by PVIg-Sf9 in neonatal mice model for PV. PV sera were incubated either with PVIg-Sf9 supernatant or control supernatant, then IgG was prepared, concentrated, and injected into neonatal mice. Mice injected with PV sera treated with control supernatant demonstrated extensive blisters and erosions ( $A$, two left mice) and showed suprabasilar acantholysis in histology $(B)$, however mice injected with PV sera treated with PVIg-Sf9 supernatant showed normal appearing healthy skin ( $A$, two right mice) as well as no apparent acantholysis in histology $(C)$.
$35 \mathrm{PV}$ sera, $10 \mathrm{PF}$ sera, $16 \mathrm{BPF}$ sera, $10 \mathrm{BP}$ sera, and five normal control sera. Because the PVIg molecules have Fc portion of human IgG1, anti-human IgG antibodies, which react with the PVIg itself, could not be used as a second antibody to detect reactivity of human sera against the PVIg molecule. Instead, after incubation of blotted membranes with human sera, mouse anti-human IgG4 monoclonal antibody was used to detect bound human IgG4, which is a dominant subclass of PV IgG (37-41), then alkaline-phosphatase conjugated goat antimouse IgG antibodies were used to visualize their reactivities:

Remarkably, the PVIg-COS7 chimeric molecule was recognized by all the 35 PV sera tested, but not by any of 36 disease-control sera nor five normal control sera (Fig. $3 A$ ). We conclude from these data that the chimeric construct encodes the expected recombinant molecule that, even when denatured for immunoblotting, contains epitopes identified by all PV sera, but not by any control sera.

Production and secretion of the PVA extracellular domain by baculovirus in $S f 9$ insect cells. The above studies confirmed that the PVIg chimeric molecule expressed in COS7 cells contains more epitopes than the bacterial fusion proteins used in the previous study (20). We next wanted to determine if this secreted molecule contained pathogenic epitopes by absorption studies with human PV sera. However, for these types of studies we needed to produce more protein than the small quantities $(\sim 0.1-0.5 \mu \mathrm{g} / \mathrm{ml})$ produced by transient transfection of COS7 cells. We therefore cloned the chimeric cDNA into a baculovirus transfer vector that could be used to produce large quantities of protein in insect Sf9 cells.

Infection of Sf 9 cells with a recombinant baculovirus containing PVIg coding sequences resulted in secretion of the chimeric molecule, PVIg-Sf9, in cultured media, whose concentration was $\sim 5-10 \mu \mathrm{g} / \mathrm{ml}, 20-100$-fold more than that of PVIg-COS7. Purified PVIg-Sf9 was examined by immunoblot and detected as a doublet, whose molecular weights were 107 and $110 \mathrm{kD}$ (Fig. 2, lane 2). This doublet was thought to be products with and without proteolytic processing of the prosequence. In baculovirus expression system proteolytic processing sometimes is not efficient, particularly if synthesis is very high (42). Matured PVIg-Sf9, the lower band of the doublet, is a little smaller than PVIg-COS7 (Fig. 2, lanes 1 and 2). This may be due to the different way of glycosylation between in COS7 cells and in Sf9 cells. Sf9 cells cannot add a complex form of glycosylation.

Precursor proteins of PVIg-Sf9 in Sf9 cell extracts were detected as a major $110-\mathrm{kD}$ band and a minor $97-\mathrm{kD}$ band, which were considered to be products with and without glycosylation (Fig. 2, lane 3). Under nonreduced condition PVIgSf9 in the supernatant was detected as a doublet of 210 and $190 \mathrm{kD}$ (Fig. 2, lane 4). These findings indicate that PVIg-Sf9 is glycosylated and secreted as a dimer, presumably through disulfide bonds in hinge region.

The reactivity of the secreted chimeric molecule, PVIg-Sf9, 
Table II. Passive Transfer of PVIg-Sf 9 Treated PV Antibodies to Neonatal Mice

\begin{tabular}{lcc}
\hline \multicolumn{1}{c}{ IgG injected } & $\begin{array}{c}\text { Number of mice } \\
\text { injected }\end{array}$ & $\begin{array}{c}\text { Number of mice } \\
\text { with gross blisters }\end{array}$ \\
\hline PV serum No. 11 absorbed with: & & \\
PVIg-Sf9 & 3 & 0 \\
Control supernatant & 3 & 2 \\
PV serum No. 12 absorbed with: & 13 & 0 \\
PVIg-Sf9 & 12 & 12 \\
Control supernatant & & \\
PV serum No. 13 absorbed with: & 8 & 0 \\
PVIg-Sf9 & 8 & 6 \\
Control supernatant & & \\
\end{tabular}

against PV and control sera was examined (Fig. $3 \mathrm{~B}$ ). The PVIg-Sf 9 was also recognized by all the $35 \mathrm{PV}$ sera tested as strongly as the PVIg-COS7, but not by any 36 disease control nor five normal control sera. Several PV sera reacted better or only to the lower band of the PVIg-Sf9 doublet. The cleavage of the prosequence may also contribute to the conformation of the extracellular domain of PVA, which was recognized by several PV sera even in denatured condition.

These findings indicate that the baculovirus product, PVIgSf 9, has equivalent epitopes to PVIg-COS7 and that a large quantity of the PVA baculovirus protein could be produced for the absorption study with PV patients' sera.

Absorption of pathogenic autoantibodies from $P V$ sera by the extracellular domain of PVA produced by baculovirus. We next wanted to determine whether PVIg-Sf9 generates most or all epitopes recognized by PV sera, which contain heterogeneous antibodies reacting to different parts of the PVA. To avoid any denaturing process, cultured media of Sf 9 cells infected with PVIg-Sf 9 recombinant virus were used to incubate with $17 \mathrm{PV}$ sera, and immunofluorescence titers on normal human epidermis were examined. Cryo-sectioned normal human skin should represent nondenatured PVA with the proper conformation. Conditioned media of noninfected Sf 9 cells were used as a control supernatant to incubate with PV sera.

Strikingly, in 6 out of 17 PV sera tested, the reactivity of PV sera against keratinocyte cell surface was completely removed by the incubation with PVIg-Sf9 (Fig. 4, $A-D$; Table I). The titers of the other 10 PV sera were also reduced significantly, but to various ranges: $2-32$-fold. Only one PV serum showed no reduction of the titer even after treatment with PVIgSf9. The mean titers of control and PVIg-Sf9 treated PV sera were $664 \pm 121$ and $146 \pm 74$, respectively, and the difference was statistically significant (Wilcoxon, $P<0.005$ ). The incubation of PF sera with PVIg-Sf9 did not alter the titers at all (Fig. 4, $E$ and $F$; Table I). These findings indicate that PVIgSf 9 has the conformation very close to the authentic PVA and has most (or all for several PV sera) of the epitopes of the PVA, including conformational ones.

Furthermore, once PVIg-Sf 9 was denatured by acidic buffer (0.5 M glycine, $0.15 \mathrm{M} \mathrm{NaCl}, \mathrm{pH} 2.3$ ) or detergent-containing buffer (1\% SDS in TBS), PVIg-Sf9 was no longer able to block the reactivity of PV sera on normal human epidermis and did not reduce immunofluorescence titers significantly (data not
Table III. Titration of the Pathogenic Activity of Injected PV Antibodies

\begin{tabular}{lcc}
\hline \multicolumn{1}{c}{ IgG injected } & $\begin{array}{c}\text { Number of mice } \\
\text { injected }\end{array}$ & $\begin{array}{c}\text { Number of mice } \\
\text { with gross blisters }\end{array}$ \\
\hline $\begin{array}{l}\text { Control-absorbed PV serum No. } 12 \\
\text { 1× dilution }\end{array}$ & 5 & \\
$2 \times$ dilution & 6 & 5 \\
$4 \times$ dilution & 4 & 6 \\
$8 \times$ dilution & 4 & 0 \\
PVIg-Sf9-absorbed PV serum No. 12 & & \\
1× dilution & 5 & 0 \\
$2 \times$ dilution & 4 & 0 \\
$4 \times$ dilution & 3 & 0 \\
$8 \times$ dilution & 3 & 0 \\
\end{tabular}

shown), indicating the importance of the conformation of PVIgSf 9 in antigenicity of PVA.

Finally, we wanted to determine whether the PVIg-Sf9 is capable of absorbing pathogenic autoantibodies from PV sera. For this purpose, three PV sera (Table I, 11, 12, and 13) were incubated with culture supernatant of either Sf 9 cells infected with PVIg-Sf 9 recombinant virus or noninfected Sf 9 cells, then IgG fraction was prepared by $40 \%$ ammonium sulfate precipitation and concentrated to inject neonatal mice.

The PV IgG incubated with the control supernatant demonstrated extensive blisters and erosions in neonatal mice, whereas all the three PV IgGs incubated with PVIg-Sf 9 supernatant lost the pathogenic activity of inducing gross blisters (Fig. $5 \mathrm{~A}$ and Table II). The skin specimen of mice injected with PV IgG treated with control supernatant showed suprabasilar acantholysis, characteristic histological finding of PV (Fig. $5 \mathrm{~B}$ ). In contrast, mice injected with PV IgG treated with PVIg-Sf9 supernatant showed intact epidermis (Fig. $5 C$ ), although focal suprabasilar acantholysis could be detected just occasionally by search under microscopy. The deposition of human PV IgG on keratinocyte cell surface in vivo was observed in both groups of mice and the intensity of staining was comparable (data not shown). The titers of PV IgG in mice injected with PVIg-Sf9treated sera were 1:80 to 1:160, which were 2-4-fold lower than that of mice injected with control-supernatant-treated sera. These titers of the mice were compatible with the original titers of the sera after the treatment with PVIg-Sf9 or control supernatant (Table I).

Furthermore, to titrate the pathogenic activity of the IgG injected, serial dilution of the concentrated IgG of PV serum No. 12, which was incubated with control or PVIg-Sf9 supernatant, was made and injected into neonatal mice (Table III). PV IgG incubated with control supernatant was able to induce gross blisters in all the mice injected even at twofold dilution, and it lost pathogenic activity at eightfold dilution. None of the diluted PV IgG incubated with PVIg-Sf 9 caused blisters.

These findings demonstrate that the PVIg-Sf 9 recombinant protein is capable of absorbing pathogenic autoantibodies from PV patients' sera and preventing gross blister formation in the neonatal mouse model.

\section{Discussion}

In this study we aimed to produce a recombinant protein of PVA, which can absorb pathogenic autoantibodies from PV 
patients' sera. The previously produced bacterial fusion proteins for PVA represented only the sequential epitopes, but not most of the conformational epitopes, and failed to absorb out pathogenic antibodies from PV sera (20). Therefore, we attempted to produce PVA recombinant proteins in eucaryotic cells, which can mediate posttranslational modifications like glycosylation, proteolytic processing, and proper protein folding. We constructed a chimeric molecule of the entire extracellular domain of PVA tailed with the constant region of human IgG1, termed PVIg, and produced it in COS7 cells and in Sf9 insect cells. PVIg-COS7 and PVIg-Sf9 were both recognized by all the PV sera tested, but by none of any disease or normal control sera. Furthermore, PVIg-Sf9 was able to absorb out pathogenic autoantibodies from PV patients' sera and prevented gross blister formation in the well established neonatal mouse model for pemphigus. Compared with bacterial fusion proteins, the recombinant proteins produced in eucaryotic cells are much more likely to contain more epitopes, including pathologically significant ones.

However, once PVIg-Sf 9 was denatured by acidic buffer or detergent, it lost blocking activity against PV antibodies, as determined by immunofluorescence staining of normal human epidermis. Taken together with the observation of the bacterial fusion proteins of PVA (20), we concluded that the conformation of PVA plays an important role in the antigenicity and pathogenicity of pemphigus.

When PV sera were preincubated with PVIg-Sf9, about one third of sera completely lost the reactivity against keratinocyte cell surface of normal human epidermis as detected by immunofluorescence. These PV sera are mostly derived from clinically mild cases, which had only oral erosions or localized skin lesions and responded well to systemic corticosteroid treatment (Table I). The other PV sera, which retained some reactivity against keratinocyte cell surface although the titers were significantly reduced after the treatment with PVIg-Sf9, are mainly from clinically severe cases, which had generalized blisters and erosions for a long period of time or were resistant against conventional systemic corticosteroid treatment (Table I). The three PV sera used for the neonatal mice study are in this group, but the preincubation with PVIg-Sf9 removed pathogenic activity of these PV sera. These observations suggest that along the progress of the disease patients may raise antibodies against nonpathogenic epitopes of the extracellular domain or the cytoplasmic domain of PVA, or even against other molecules expressed on the cell surface, as an epiphenomenon. Furthermore, it is interesting that the PV serum No. 17, whose titers were not changed even after the absorption with PVIg-Sf9 (Table I), reacted strongly with both PVA and Dsg1 by immunoblot (data not shown), suggesting that the remaining reactivity of the PV serum on keratinocyte cell surface are derived from IgG against Dsg1.

The demonstration that large quantities of the extracellular domain of PVA with the proper conformation can be produced by baculovirus may have several important implications. From a clinical point of view, ELISA test using PVIg-Sf9 as an antigen source would be a sensitive and specific diagnostic tool. Scores of this ELISA should correlate even better with disease activity than currently used immunofluorescence tests with normal human skin because IgG titers can only be measured against the pathogenic extracellular domain of PVA. Furthermore, as a new type of treatment, antigen-specific plasmapheresis with a
PVIg-Sf 9 column would be developed, which could specifically remove pathogenic IgG against PVA from patients' circulation with minimal side effects. From a biological point of view, this PVA recombinant protein would be valuable to study adhesion function of PVA in cultured keratinocyte and also to do fine epitope mapping of PVA.

\section{Acknowledgments}

We would like to thank Dr. John R. Stanley for insightful discussions throughout the course of this work and for reviewing this manuscript. We also thank Dr. Lois K. Miller for providing pEVmod baculovirus transfer vector, Drs. Satoshi Nakamura and Kazuhiko Souma for pTJ5, a plasmid-containing cDNA for human IgG1 constant region. We thank Dr. Reinhard Kirnbauer and Dr. Atsushi Takayanagi for helpful discussions on baculovirus expression, Dr. Shinobu Gamou for helpful suggestions on general issues, and Drs. Mark C. Udey and Akinao Nose for valuable discussions at the initiation of this project. We also thank Mr. Takashi Kimura for assistance with neonatal mouse studies and Miss Minae Makino for immunofluorescence staining. We are grateful to Dr. Reiko Harada for her support during this project.

This work was supported by Grant-In-Aid for Scientific Research from the Ministry of Education, Science, and Culture of Japan (05404036, 04454289), from Monbusho International Scientific Research Program (05044186), and the Ministry of Health and Welfare of Japan.

\section{References}

1. Stanley, J. R. 1989. Pemphigus and pemphigoid as paradigms of organspecific, autoantibody-mediated diseases. J. Clin. Invest. 83:1443-1448.

2. Sams, W., and R. E. Jordon. 1971. Correlation of pemphigoid and pemphigus antibody titres with activity of disease. Br. J. Dermatol. 84:7-13.

3. Merlob, P., A. Metzker, B. Hazaz, H. Rogovin, and S. H. Reisner. 1986. Neonatal pemphigus vulgaris. Pediatrics. 78:1102-1105.

4. Schiltz, J. R., and B. Michel. 1976. Production of epidermal acantholysis in normal human skin in vitro by the IgG fraction from pemphigus serum. $J$. Invest. Dermatol. 67:254-260.

5. Hashimoto, K., K. M. Shafran, P. S. Webber, G. S. Lazarus, and K. H. Singer. 1983. Anti-cell surface pemphigus autoantibody stimulates plasminogen activator activity of human epidermal cells. J. Exp. Med. 157:259-272.

6. Anhalt, G. J., R. S. Labib, J. J. Voorhees, T. F. Beals, and L. A. Diaz. 1982. Induction of pemphigus in neonatal mice by passive transfer of IgG from patients with the disease. N. Engl. J. Med. 306:1189-1196.

7. Stanley, J. R., L. Koulu, and C. Thivolet. 1984. Distinction between epidermal antigens binding pemphigus vulgaris and pemphigus foliaceus autoantibodies. J. Clin. Invest. 74:313-320.

8. Eyre, R. W., and J. R. Stanley. 1988. Identification of pemphigus vulgaris antigen extracted from normal human epidermis and comparison with pemphigus foliaceus antigen. J. Clin. Invest. 81:807-812.

9. Jones, J., K. M. Yokoo, and R. D. Goldman. 1986. Further analysis of pemphigus autoantibodies and their use in studies on the heterogeneity, structure, and function of desmosomes. J. Cell Biol. 102:1109-1117.

10. Hashimoto, T., M. M. Ogawa, A. Konohana, and T. Nishikawa. 1990. Detection of pemphigus vulgaris and pemphigus foliaceus antigens by immunoblot analysis using different antigen sources. J. Invest. Dermatol. 94:327-331.

11. Amagai, M., V. Klaus-Kovtun, and J. R. Stanley. 1991. Autoantibodies against a novel epithelial cadherin in pemphigus vulgaris, a disease of cell adhesion. Cell. 67:869-877.

12. Takeichi, M. 1990. Cadherins: a molecular family important in selective cell-cell adhesion. Annu. Rev. Biochem. 59:237-252.

13. Takeichi, M. 1991. Cadherin cell adhesion receptors as a morphogenetic regulator. Science (Wash. DC). 251:1451-1455.

14. Koch, P. J., M. J. Walsh, M. Schmelz, M. D. Goldschmidt, R. Zimbelmann, and W. W. Franke. 1990. Identification of desmoglein, a constitutive desmosomal glycoprotein, as a member of the cadherin family of cell adhesion molecules. Eur. J. Cell. Biol. 53:1-12.

15. Goodwin, L., J. E. Hill, K. Raynor, L. Raszi, M. Manabe, and P. Cowin. 1990. Desmoglein shows extensive homology to the cadherin family of cell adhesion molecules. Biochem. Biophys. Res. Commun. 173:1224-1230.

16. Nilles, L. A., D. Parry, E. E. Powers, B. D. Angst, R. M. Wagner, and 
K. J. Green. 1991. Structural analysis and expression of human desmoglein: a cadherin-like component of the desmosome. J. Cell Sci. 99:809-821.

17. Wheeler, G. N., A. E. Parker, C. L. Thomas, P. Ataliotis, D. Poynter, J. Arnemann, A. J. Rutman, S. C. Pidsley, F. M. Watt, D. A. Rees, R. S. Buxton, and A. I. Magee. 1991. Desmosomal glycoprotein DGI, a component of intercellular desmosome junctions, is related to the cadherin family of cell adhesion molecules. Proc. Natl. Acad. Sci. USA. 88:4796-4800.

18. Ozawa, M., and R. Kemler. 1990. Correct proteolytic cleavage is required for the cell adhesive function of uvomorulin. J. Cell Biol. 111:1645-1650.

19. Nose, A., K. Tsuji, and M. Takeichi. 1990. Localization of specificity determining sites in cadherin cell adhesion molecules. Cell. 61:147-155.

20. Amagai, M., S. Karpati, R. Prussick, V. Klaus-Kovtun, and J. R. Stanley. 1992. Autoantibodies against the amino-terminal cadherin-like binding domain of pemphigus vulgaris antigen are pathogenic. J. Clin. Invest. 90:919-926.

21. Barkas, T., A. Mauron, B. Roth, C. Alliod, S. J. Tzartos, and M. Ballivet. 1987. Mapping the main immunogenic region and toxin-binding site of the nicotinic acethylcholine receptor. Science (Wash. DC). 235:77-80.

22. Tanaka, M., T. Hashimoto, M. Amagai, N. Shimizu, N. Ikeguchi, T. Tsubata, A. Hasegawa, K. Miki, and T. Nishikawa. 1991. Characterization of bullous pemphigoid antibodies by use of recombinant bullous pemphigoid antigen proteins. J. Invest. Dermatol. 97:725-728.

23. Allen, E. M., G. J. Giudice, and L. A. Diaz. 1993. Subclass reactivity of pemphigus foliaceus antiantibodies with recombinant human desmoglein. J. Invest. Dermatol. 100:685-691.

24. Miller, J. E., M. J. Rico, and R. P. Hall. 1993. IgG antibodies from patients with bullous pemphigoid bind to fusion proteins encoded by BPAg1 cDNA. $J$. Invest. Dermatol. 101:779-782.

25. Benjamin, D. C., J. A. Berzofsky, I. J. East, F. R. N. Gurd, C. Hannum, S. J. Leach, E. Margoliash, J. G. Michael, A. Miller, E. M. Prager, M. Reichlin, E. E. Sercarz, S. J. Smith-Gill, P. E. Todd, and A. C. Wilson. 1984. The antigenic Structure of proteins: a reappraisal. Annu. Rev. Immunol. 2:67-101.

26. Amagai, M., S. Karpati, V. Klaus-Kovtun, M. C. Udey, and J. R. Stanley. 1994. The extracellular domain of pemphigus vulgaris antigen (Desmoglein 3 ) mediates weak homophilic adhesion. J. Invest. Dermatol. 102:402-408.

27. Nakamura, S., T. Masegi, K. Kitani, A. Kudo, T. Watanabe, and Y. Ichikawa. 1988. Production of the human immunoglobulin $\gamma_{1}$ chain constant region polypeptide in Escherichia coli. J. Biotechnol. 8:141-148.

28. Wang, X., B. G. Ooi, and L. K. Miller. 1991. Baculovirus vectors for multiple gene expression and for occluded virus production. Gene (Amst.). 100:131-137.
29. Kozak, M. 1987. An analysis of 5'-coding sequences from 699 vertebrate messenger RNAs. Nucleic Acids Res. 15:8125-8148.

30. O'reilly, D. R., L. K. Miller, and V. A. Luckow. 1992. Baculovirus expression vectors: a laboratory manual. W. H. Freeman and Company. New York. 98-103.

31. Alzari, P. M., M. B. Lascombe, and R. J. Poljak. 1988. Three dimensional structure of antibodies. Annu. Rev. Immunol. 6:555-580.

32. Aruffo, A., I. Stamenkovic, M. Melnick, C. B. Underhill, and B. Seed. 1990. CD44 is the principal cell surface receptor for hyaluronate. Cell. 61:13031313

33. Aruffo, A., W. Kolanus, G. Walz, P. Fredman, and B. Seed. 1991. CD62/ P-selectin recognition of myeloid and tumor cell sulfatides. Cell. 67:35-44.

34. Linsley, P. S., W. Brady, L. Grosmaire, A. Aruffo, N. K. Damle, and J. A. Ledbetter. 1991. Binding of the B cell activation antigen B7 to CD28 costimulates $\mathrm{T}$ cell proliferation and interleukin 2 mRNA accumulation. J. Exp. Med. 173:721-730.

35. Linsley, P. S., W. Brady, M. Urnes, L. S. Grosmaire, N. K. Damle, and J. A. Ledbetter. 1991. CTLA-4 is a second receptor for the B cell activation antigen B7. J. Exp. Med. 174:561-569.

36. Levinovitz, A., J. Muhlhoff, S. Isenmann, and D. Vestweber. 1993. Identification of a glycoprotein ligand for E-selectin on mouse myeloid cells. J. Cell Biol. 121:449-459.

37. Yamada, H., T. Hashimoto, and T. Nishikawa. 1989. IgG subclasses of intercellular and basement membrane zone antibodies: the relationship to the capability of complement fixation. J. Invest. Dermatol. 92:585-587.

38. Ogawa, M. M., T. Hashimoto, T. Nishikawa, and R. M. Castro. 1989. IgG subclasses of intercellular antibodies in Brazilian pemphigus foliaceus-the relationship to complement fixing capability. Clin. Exp. Dermatol. 14:29-31.

39. Rock, B., C. R. Martins, A. N. Theofilopoulos, R. S. Balderas, G. J. Anhalt, R. S. Labib, S. Futamura, E. A. Rivitti, and L. A. Diaz. 1989. The pathogenic effect of IgG4 autoantibodies in endemic pemphigus foliaceus (fogo selvagem). N. Engl. J. Med. 320:1463-1469.

40. Kim, Y. H., W. D. Geoghegan, and R. E. Jordon. 1990. Pemphigus immunoglobulin $\mathrm{G}$ subclass autoantibodies: studies of reactivity with cultured human keratinocytes. J. Lab. Clin. Med. 115:324-331.

41. Shirakata, Y., S. Shiraishi, K. Sayama, and Y. Miki. 1990. Subclass characteristics of IgG autoantibodies in bullous pemphigoid and pemphigus. $J$. Dermatol. 17:661-666.

42. Kuroda, K., M. Veit, and H. D. Klenk. 1991. Retarded processing of influenza virus hemagglutinin in insect cells. Virology. 180:159-165. 